\title{
Measuring Health Literacy Among Adults with HIV Infection in Mozambique: Development and Validation of the HIV Literacy Test
}

\author{
José A. Tique ${ }^{1}\left(\mathbb{D} \cdot\right.$ Leigh M. Howard $^{2} \cdot$ Sandra Gaveta $^{3} \cdot$ Mohsin Sidat $^{3} \cdot$ \\ Russell L. Rothman ${ }^{4} \cdot$ Sten H. Vermund ${ }^{4} \cdot$ Philip J. Ciampa ${ }^{5}$
}

Published online: 10 March 2016

(c) The Author(s) 2016. This article is published with open access at Springerlink.com

\begin{abstract}
The role of health literacy on HIV outcomes has not been evaluated widely in Africa, in part because few appropriate literacy measures exist. We developed a 16-item scale, the HIV Literacy Test (HIV-LT) to assess literacy-related tasks needed to participate in HIV care. Items were scored as correct or incorrect; higher scores indicated higher literacy skill (range 0-100 \%). We tested internal reliability (Kuder-Richardson coefficient) of the HIV-LT in a convenience sample of 319 Portuguesespeaking, HIV infected adults on antiretroviral treatment in Maputo, Mozambique. Construct validity was assessed by a hypothetical model developed a priori. The HIV-LT was reliable and valid to measure participants' literacy skills. The mean HIV-LT score was $42 \%$; literacy skills applicable to HIV care were challenging for many participants. The HIV-LT could be used to assess the relationship of literacy and HIV-related outcomes in diverse settings, and
\end{abstract}

Electronic supplementary material The online version of this article (doi:10.1007/s10461-016-1348-3) contains supplementary material, which is available to authorized users.

José A. Tique

jose.tique@fgh.org.mz; jose.a.tique@vanderbilt.edu

1 National STI's and HIV Program, Ministry of Health, Avenida Eduardo Mondlane/Salvador Allende, Maputo, Mozambique

2 Department of Pediatrics, Vanderbilt University School of Medicine, Nashville, USA

3 Community Health Department, Eduardo Mondlane University, Maputo, Mozambique

4 Departments of Pediatrics and Medicine, Vanderbilt University School of Medicine, Nashville, USA

5 Harvard Medical School, Harvard University, Boston, USA evaluate interventions to improve health communication for those in HIV care.

Keywords Health literacy · Mozambique $\cdot$ HIV $\cdot$ Health communications - Antiretroviral therapy · Psychometrics . Poverty

\section{Introduction}

Through substantial international efforts, there has been an unprecedented increase in access to HIV treatment in subSaharan Africa, where $70 \%$ of the world's 35 million HIV infected people reside [1]. Despite significant advances in antiretroviral therapy (ART) coverage, many patients still experience significant mortality after treatment initiation [2], and suboptimal adherence remains an important threat for opportunistic infections and HIV disease progression [3, 4]. While numerous barriers to patients' adherence and retention to care in sub-Saharan Africa have been described [5-7], the role of health literacy on HIV related behaviors and outcomes has been a relatively neglected research topic.

Overall literacy skills include an individual's ability to read, write and comprehend written language (print literacy), speak and understand spoken language (oral literacy) and understand and use numbers in daily life (numeracy) $[8,9]$. Health literacy, a subset of overall literacy skills that is highly correlated with it, has been defined as "the degree to which individuals have the capacity to obtain, process and understand basic health information and services needed to make appropriate health decisions" [10]. Low or inadequate health literacy is common even in high-income countries such as the United States, where 90 million people are estimated to be affected [8]. Studies have shown that limited health literacy is associated with suboptimal 
health outcomes, particularly in chronic conditions such as diabetes and HIV [8, 11-13]. Despite the high levels of illiteracy found in sub-Saharan Africa, affecting up to $40 \%$ of its population [14], studies examining the association between literacy or health literacy and health outcomes have been limited in number, scope and spread [15-20].

Successfully managing HIV infection requires from individuals the ability to access medical care, understand medical recommendations and execute treatment plans; these skills may each be influenced by an individual's health literacy [8]. Evidence from the US has shown that health literacy skills are important mediators of HIV-related knowledge, behaviors and outcomes [21-28]. Studies suggest that individuals with HIV who have limited health literacy have less HIV knowledge [21-24], less ability to correctly manage HIV medication [25, 29], and lower likelihood of achieving undetectable viral loads compared to those with adequate health literacy skills [21, 27]. Most studies have demonstrated an association between limited health literacy and lower adherence to ART [26, 27, 3033], but some did not find such a relationship [23, 34, 35].

In the few known studies examining the relationship between health literacy and HIV related behaviors and outcomes in sub-Saharan Africa, population literacy data and overall literacy skills have been used as surrogates for health literacy $[19,20]$. While these types of data may not require specialized testing, they do not measure the specific literacy skills needed to participate in health-related activities. This moves away from the definition of health literacy that relates to an individual's possession of requisite skills for making health-related decisions, meaning that health literacy must always be examined in the context of the specific tasks that need to be accomplished [51]. This underscores the need for measures that are applied to a disease or health context.

In Mozambique, where the 2009 prevalence of HIV among adults was $11.5 \%$ [36], census data report that only $55 \%$ of the population were literate in 2007 [14]. We do not know how such profound levels of limited literacy skills may impact the ability of adults to self-manage diseases like HIV infection in low-income settings such as Mozambique, or what impact limited health literacy may have on health behaviors and outcomes. The objective of this study was to develop and rigorously test the psychometric properties of a novel measure of health literacy for adults with HIV, the HIV Literacy Test (HIV-LT).

\section{Methods}

\section{Scale Development}

We developed the 16-item HIV-LT to assess common literacy and numeracy-related tasks that adults with HIV infection in Mozambique must perform in order to participate in HIV-related care. These tasks include the ability to dose oral medications, manage appointments, and understand the risk of HIV transmission and of treatment side effects. Key literacy and numeracy skills tested in the HIV-LT include document/print literacy, addition, multiplication, division, numeration/numerical hierarchy, fractions, and percentages. Preliminary work measuring general literacy and numeracy [19] and review of existing measures of health literacy applied to other diseases informed item development [37-39]. In the initial development phase, a pool of 35 items was generated. Scale items included clinical materials (such as prescription cards) used during routine HIV care in Mozambique whenever appropriate. Items were generated in English and translated into Portuguese by a native speaker and official translator, then back-translated to ensure content fidelity [40, 41]. To limit content redundancy, our panel of experts reduced this initial pool to 16 items that had high face validity to assess a range of literacy skills needed to participate in HIV care.

In the second phase of development, we conducted cognitive-based assessments with 20 Portuguese-speaking adults accessing HIV care and receiving ART at two clinics in Maputo, Mozambique to get feedback about the 16 candidate items. Participants with a level of formal education that ranged from none to 12 years were selected for the assessment. Participants were asked to evaluate the content, clarity, and readability of each item. Suggestions to simplify some of the medical terms used in the items and to apply culturally appropriate language were incorporated into the revision of scale items used in the study. No items were abandoned in this process. In order to ascertain health literacy and numeracy even for those participants with very limited literacy and numeracy, and assess participant's skills in a format that is commonly used in usual practice, the first five item stems in the HIV-LT were read out loud for the participants. The rest of the items in the scale were self-administered. Item responses are defined as correct or incorrect with higher scores indicating higher literacy skill (range 0-100\%). Since there is no established minimum or maximum HIV treatment literacy threshold in the literature (and would likely vary by disease and local context), we did not define these score values in the HIV-LT. There was no time limit for responding to the questions (sample HIVLT questions in Fig. 1).

The third phase of development sought to assess the internal reliability and construct validity of the HIV-LT in a cross-section of adults on treatment for HIV infection in Maputo, Mozambique. Since there is no gold standard for HIV health literacy and numeracy, we adapted and used a model containing factors that would be expected to associate with health literacy to evaluate construct validity of 


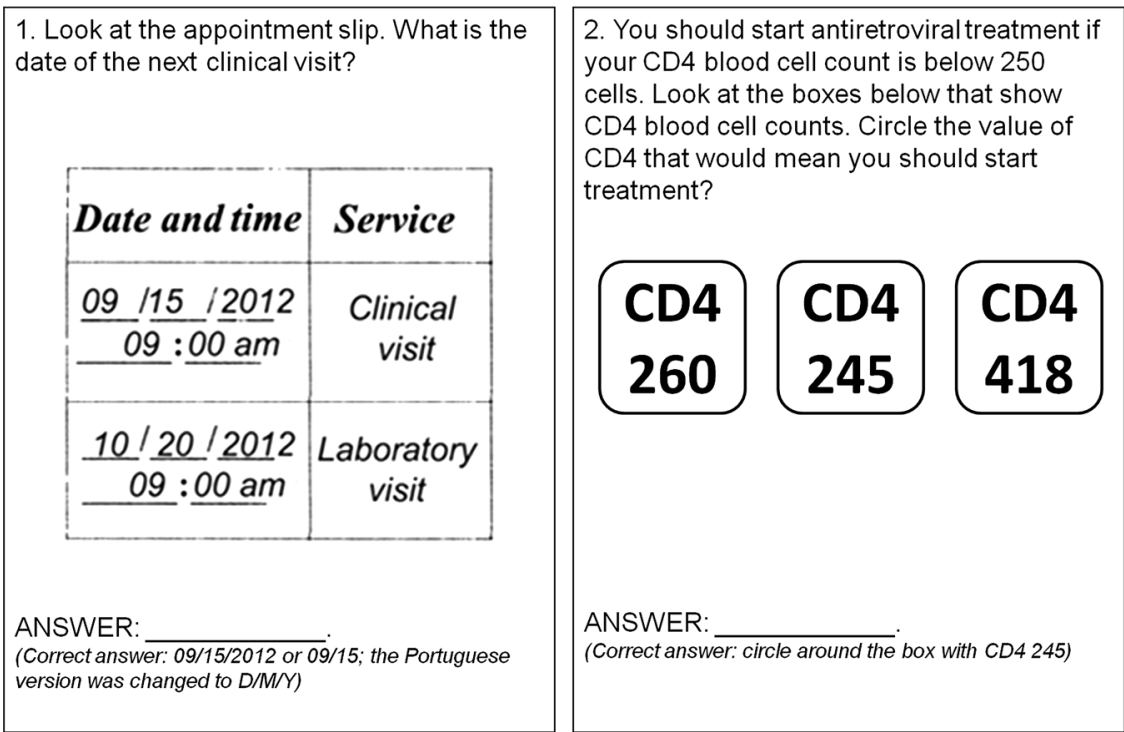

3. Look at the medicine card below. You take your breakfast at $7 \mathrm{am}$. What time would you take your morning pill?

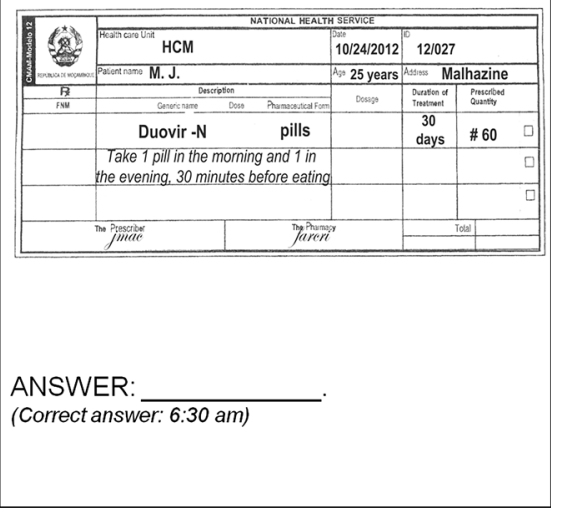

Fig. 1 Sample items from the HIV Literacy Test (HIV-LT)

the HIV-LT. Seven factors were selected a priori to test construct validity within this hypothetical model (Fig. 2). We hypothesized that higher HIV-LT scores would correlate with higher general literacy and numeracy skill, more education, higher income, work outside the home, and use of Portuguese as the primary language spoken at home. We also hypothesized that higher HIV-LT scores would be associated with higher levels of adherence to ART.

In the final phase of scale development, we used a split sample analysis to identify a shortened, more clinically useful 10-item version of the HIV-LT, the HIV-LT10. The data were randomly split into two smaller sub-samples, and we applied principal component factor analysis in subsample 1 to determine which items to include in the HIVLT10. Items with $<0.5$ loading on the primary component, and those that had $>80 \%$ or $<10 \%$ of participants answering correctly were discarded. Two items that had been deemed a priori to have high content validity were added back, bringing the total number of items to 10 . We used the sub-sample 2 to confirm the internal reliability and construct validity of the HIV-LT10. Internal reliability of the HIV-LT10 was evaluated by the Kuder-Richardson coefficient (KR-20), and its construct validity was assessed by establishing correlations with the original 16-item scale
Fig. 2 Model depicting constructs used to establish validity of the HIV Literacy Test

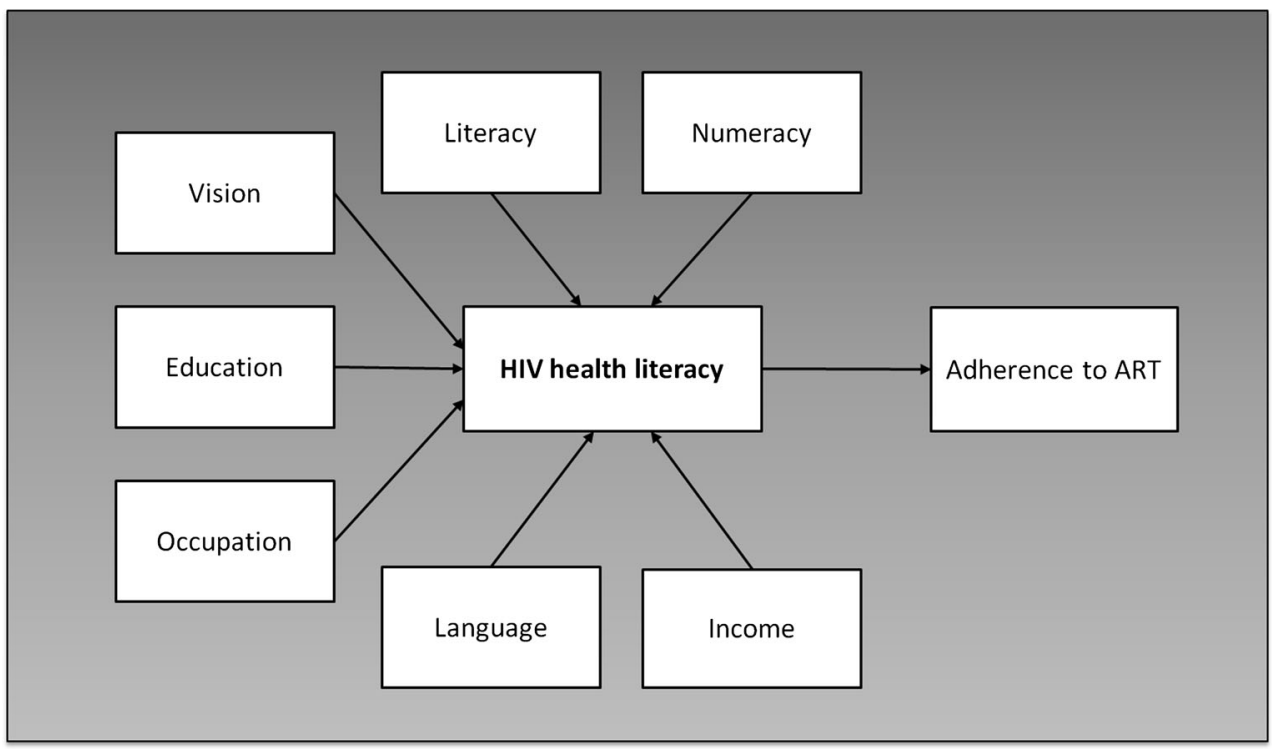


and the seven variables selected a priori to test construct validity.

\section{Study Design, Setting and Participants}

We used a cross-sectional study design to test the psychometric properties of the HIV-LT. From August to November 2012, we recruited a convenience sample of 319 adults from two clinics that provide HIV-related care: (1) the Polana Caniço health center, an outpatient care facility in the city of Maputo, Mozambique, and (2) the Marracuene health center, $40 \mathrm{~km}$ away from Maputo, in a district with a more rural population. Two study investigators who are native Portuguese-speakers (JT, SG) were responsible for participant recruitment and survey administration. Participants were included if they were between 18 and 49 years of age, had an established diagnosis of HIV infection, and had been on ART for at least 3 months. Participants were excluded from the study if they were unable to communicate in basic Portuguese, and because the HIV-LT requires some reading and writing ability, participants that demonstrated a visual acuity of worse than 20/50 (if uncorrected) as determined with a pocket vision screener (Rosenbaum, Graham-Field Surgical Co, Inc, New Hyde Park, NY, USA) were also excluded.

\section{Measures}

\section{Demographics}

Socio-demographic information was collected by structured interview and included age, primary language spoken at home, distance from home to the clinic, education, occupation, and income. HIV disease stage information was extracted from clinical records.

\section{General Literacy and Numeracy}

General literacy and numeracy were measured with a Portuguese-language adaptation of the Wide Range Achievement Test, version 3 (WRAT-3) word reading and numeracy sub-scales [42] that have been previously validated for use in Mozambican women [19]. The word reading subscale consists of a list of 15 letters and 42 words of escalating contextual and phonetic complexity and measures general literacy skill. Participants attempt to read each item on the list and are scored for proper pronunciation; scores range from 0 to 57 . The arithmetic subscale consists of two parts, and measures general numeracy skill (scores range from 0 to 30 ). Part one consists of 15 orally administered items augmented by a visual aid card. A perfect score of 15 correctly answered items corresponded to the US equivalent of kindergarten or less skills. Part two consists of 15 self-administered arithmetic problems of escalating difficulty.

\section{0-Day Adherence to ART}

We extracted pharmacy refill data for the preceding 3 months from pharmacy registers to calculate a measure of ART adherence, the medication possession ratio (MPR) [43]. The number of days that a participant had possession of antiretroviral medication in the 90 days prior to enrollment was divided by the number of days in the defined period (90 days), and multiplied by 100 to get the percentage; this value represented the proportion of days a participant had access to medication. The MPR has been shown to be a valid estimation of maximum possible adherence in settings such as Mozambique, where ART is provided for free through a single, centralized location, minimizing the possibility of individuals receiving medication from multiple source [5].

\section{Statistical Analysis}

We report descriptive statistics as proportions, means with standard deviation (SD), or medians with interquartile range (IQR) as statistically appropriate. We evaluated internal reliability using the KR-20 [44]. We evaluated construct validity by examining the bivariate relationship between HIV-LT score and the seven factors selected a priori. We used the Spearman's rank test to assess the correlation between the HIV-LT and continuous variables, including basic word reading, arithmetic computation, education, and 90-day adherence to ART. We used Kruskal-Wallis tests and Wilcoxon rank sum tests to compare the relationship between the HIV-LT and categorical variables including language spoken at home, occupation and income.

Using a split sample approach, we performed principal component factor analysis with an orthogonal rotation to determine the presence of multiple factors and item loadings on each factor. Additional exploratory factor analyses was performed including Principal Component Analysis, Maximum Likelihood Analysis, Principal Axis Factoring, General Least Squares Analysis with Orthogonal, Oblique and Equamax Rotations where applicable, to confirm the results of the original principal component analyses. We then created a shortened 10-item scale and tested for internal reliability by the KR-20. To establish construct validity of the HIV-LT10, we tested its association with the original 16-item HIV-LT and the seven variables selected a priori.

The National Committee of Bioethics for Health in Mozambique and the Institutional Review Board of Vanderbilt University reviewed and approved the protocol for 
this study. All study participants provided informed consent prior to enrollment in the study. We collected and managed data using REDCap ${ }^{\circledR}$ electronic data capture tools hosted at Vanderbilt University [45]. We performed analyses using the STATA ${ }^{\circledR}$ statistical software package v12 (College Park, TX, USA).

\section{Results}

We approached 578 potential participants from August to November 2012; 476 gave consent, 320 were eligible and 319 completed study measures. Lack of time and inability to communicate in Portuguese were the main reasons for non-participation (Fig. 3). The mean age of participants was 35 years $(\mathrm{SD}=7)$, and most were women $(76 \%$; Table 1). Most participants (71\%) lived within $10 \mathrm{~km}$ of the clinic. Only $49 \%$ of the participants had a job outside the home, and most had a monthly income of $<6000$ meticais (US\$200 in November 2012). Participants had a mean of 6 years (SD: 4) of formal education, and only $34 \%$ used Portuguese as the primary language spoken at home. Participants had a median of 6 years since HIV diagnosis (IQR: 1-6) and median 2 years on ART (IQR: 1-4). Nearly two-thirds were in early stages of the disease (WHO stage I and II: $63 \%$ ). General literacy and numeracy median scores were skewed at 48 (IQR: 31,54 ) of 57 for general literacy, and 25 (IQR: 21, 28) of 30 for general numeracy. Compared to participants in urban Polana Caniço, participants in rural Marracuene had lower incomes, less education, and lower levels of general literacy and numeracy. Fewer participants in Marracuene had jobs outside the home or used Portuguese as the main language spoken at home.

Mean score on the HIV-LT was $42 \%$ (SD: $26 \%$, range 0-94\%). Participants in Marracuene had lower scores (mean: $33 \%$, SD: $25 \%$ ) than their peers in Polana Caniço (mean: $48 \%$, SD: $25 \%)(P \leq 0.0001)$. Table 2 displays the range of topics covered in the HIV-LT and how participants performed on each item. For example, $81 \%$ of the participants were able to determine the amount of water needed to prepare an oral rehydration solution by reading instructions on a label. Only $57 \%$ of participants were able to read the date of the next clinical visit in a commonly used appointment slip. Only $42 \%$ of the patients were able to determine the number of pills to take each morning using written instructions, and only $46 \%$ were able to tell how many pills would be needed for a 14-day trip if taking two pills a day. Even fewer (13\%) were able to interpret a commonly used prescription card with instructions for the correct time to take pills.

The HIV-LT had excellent internal consistency (KR$20=0.87)$ in this sample. As expected, higher HIV-LT scores were correlated strongly with higher general literacy $(\rho=0.8)$, higher general numeracy $(\rho=0.7)$ and more education $(\rho=0.7)(P<0.001)$. Participants who worked in agriculture, had lower income, and did not use Portuguese as the primary language at home had significantly lower HIV-LT scores relative to their peers with higher socioeconomic status and/or who used Portuguese preferentially (Table 3).

Median 90-day adherence to ART was high at $97 \%$ (IQR: 91-99 \%). HIV-LT scores did not correlate significantly with 90 -day adherence to ART ( $\rho=-0.01$, $P=0.8$ ). Adherence to ART was similarly high for those
Fig. 3 Study participant's recruitment process. ${ }^{a} A R T$ antiretroviral therapy

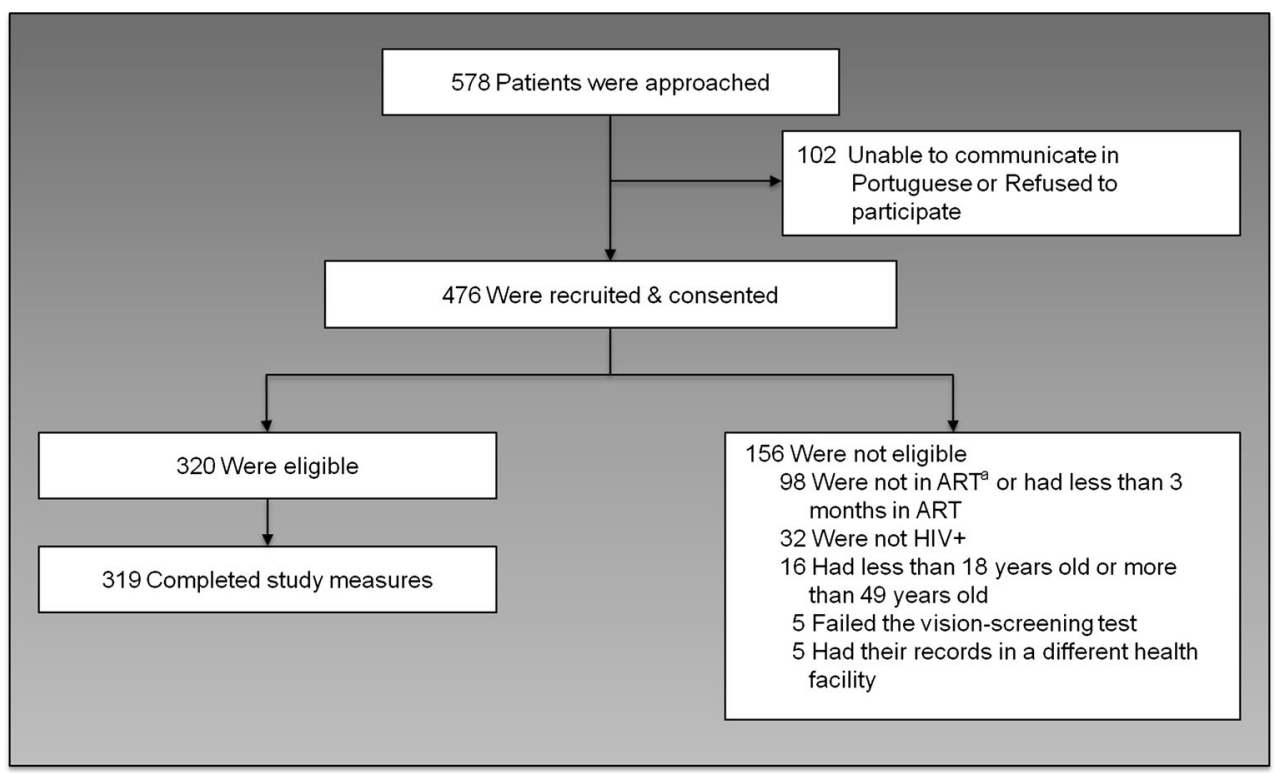


Table 1 Characteristics of 319 respondents attending HIV-related care at the urban Polana Caniço and rural Marracuene health centers in Maputo, Mozambique (August-November 2012)

\begin{tabular}{|c|c|c|c|c|}
\hline Characteristic & Total $(\mathrm{N}=319)$ & Polana Caniço $(\mathrm{N}=181)$ & Marracuene $(\mathrm{N}=138)$ & $P$ \\
\hline Age, mean (SD) & $35(7)$ & $35(7)$ & $35(6)$ & 0.74 \\
\hline Female sex, $\%$ & 76 & 76 & 75 & 0.94 \\
\hline \multicolumn{5}{|l|}{ Monthly income, \% } \\
\hline 0-5999 meticais $^{\mathrm{a}}$ & 73 & 66 & 82 & \multirow[t]{2}{*}{0.001} \\
\hline 6000 meticais or more & 27 & 34 & 18 & \\
\hline \multicolumn{5}{|l|}{ Job type, \% } \\
\hline Work outside the home & 49 & 58 & 38 & \multirow[t]{3}{*}{$<0.001$} \\
\hline Domestic or agriculture & 23 & 11 & 41 & \\
\hline No job & 27 & 31 & 21 & \\
\hline Distance from home to the clinic $>10 \mathrm{~km}, \%$ & 29 & 29 & 30 & 0.84 \\
\hline Years of education, mean (SD) & $6(4)$ & $7(4)$ & $5(3)$ & $<0.0001$ \\
\hline Portuguese primary language at home, $\%$ & 34 & 46 & 19 & $<0.001$ \\
\hline Years since HIV diagnosis, median (IQR) & $6(1-6)$ & $4(1-6)$ & $3(1-5)$ & 0.08 \\
\hline Years on ART, median (IQR) & $2(1-4)$ & $2(1-5)$ & $2(1-4)$ & 0.02 \\
\hline \multicolumn{5}{|l|}{ HIV disease stage, $\%$} \\
\hline I & 37 & 38 & 37 & \multirow[t]{4}{*}{$<0.001$} \\
\hline II & 26 & 18 & 37 & \\
\hline III & 29 & 37 & 19 & \\
\hline IV & 8 & 8 & 8 & \\
\hline 90-Day adherence to ART (MPR), \% & $97(92-99)$ & $96(87-98)$ & $98(94-100)$ & 0.02 \\
\hline General literacy score ${ }^{\mathrm{b}}$ median (IQR) & $48(31,54)$ & $51(41,55)$ & $43(10,52)$ & $<0.001$ \\
\hline General numeracy score ${ }^{\mathrm{c}}$ median (IQR) & $25(21,28)$ & $26(22,29)$ & $24(20,28)$ & 0.002 \\
\hline HIV-LT score, mean (SD) & $42(26)$ & $48(25)$ & $33(25)$ & $<0.0001$ \\
\hline
\end{tabular}

$S D$ standard deviation, IQR interquartile range, $A R T$ antiretroviral therapy, MPR medication possession ratio, HIV-LT HIV Literacy Test

${ }^{a}$ Monthly income in meticais, $0-5999 \approx \$ 0-\$ 200$ US dollars (November 2012)

b General literacy scores range from 0 to 57

c General numeracy scores range from 0 to 30

participants with below average HIV-LT scores (median: $96 \%$; IQR: $84-98 \%$ ) and those with average or above average HIV-LT scores (median: $98 \%$; IQR: 92-99\%) $(P=0.7)$.

Principal component factor analysis showed that the 16-item HIV-LT loaded on one primary factor, as demonstrated by the significant drop in eigenvalues from factor 1 to factor 2 when compared to the other factors in the scree plot (Fig. 4). The additional exploratory factor analyses that was performed also suggested that there was only one factor underlying the 16 items in the HIV-LT. The shortened HIV-LT10 instrument had high internal reliability $(\mathrm{KR}-20=0.88)$, and we saw similar bivariate relationship with each factor used to evaluate construct validity as the 16-item scale (Table 3). Correlation between the HIV-LT10 and the original 16-item HIV-LT was very strong $(\rho=0.96, P<0.0001)$.

\section{Discussion}

The HIV-LT proved both reliable and valid in measuring health literacy skills among Portuguese-speaking Mozambican adults living with HIV, and represents a novel instrument that can be used to evaluate HIV health literacy. HIV-LT scores correlated in the expected direction with six out of seven variables selected a priori to test construct validity. No significant correlation between HIV-LT score and 90-day adherence to ART was found, which may have been due to participants' surprisingly high level of adherence to ART (as measured by pharmacy refill data) in this study. The study highlights several potential challenges related to patient's ability to understand daily HIV-related self-management tasks. Participants had difficulty interpreting commonly used prescription cards, understanding the correct time and number of pills to take daily, and 
Table 2 HIV Literacy Test (HIV-LT) item content and correct responses among 319 adults on treatment for HIV infection

\begin{tabular}{|c|c|}
\hline Question topic ${ }^{\mathrm{a}}$ & Correct, \% \\
\hline 1. Report the date of the next clinical visit presented in an appointment slip & 57 \\
\hline 2. Determine the amount of water needed to prepare an oral rehydration solution by reading instructions on the label & 81 \\
\hline 3. Read a prescription card and, using the instructions, state the number of pills to take per day & 66 \\
\hline 4. Use a calendar to determine the date when a 30-day supply of pills will be completed & 5 \\
\hline 5. Using a representation of a standardized dosing cup, indicate how to measure a dose of $7.5 \mathrm{~mL}$ of zidovudine & 48 \\
\hline 6. Calculate the number of pills to take each morning using written instructions & 42 \\
\hline 7. Report the proper time to take a medication using written instructions & 55 \\
\hline 8. Interpret the value of CD4 count that would indicate the threshold for ART initiation & 50 \\
\hline 9. Interpret a dose of ART described as a fraction & 43 \\
\hline 10. Using a representation of a standardized dosing syringe, indicate how to measure a dose of $3 \mathrm{~mL}$ of zidovudine & 54 \\
\hline 11. Calculate how many days a pill supply will last using written instructions & 63 \\
\hline 12. Calculate how many pills would be needed for a 14-day trip using written instructions & 46 \\
\hline 13. Interpret a prescription card with instruction for the recommended time to take pills & 13 \\
\hline 14. Interpret the risk of mother-to-child transmission displayed in percentages & 15 \\
\hline 15. Understand the risk of opportunistic infection and malnutrition by calculating $10 \%$ of a specific body weight & 4 \\
\hline 16. Understand the risk of treatment side effects when taking cotrimoxazole & 29 \\
\hline
\end{tabular}

${ }^{a}$ Bolded items correspond to items that were included in the 10-item version of the scale (HIV-LT10)

Table 3 Association between selected respondent characteristics, HIV Literacy Test (HIV-LT) and the 10 question short HIV-LT version (HIVLT10) scores among 319 Mozambican adults on antiretroviral therapy

\begin{tabular}{|c|c|c|c|c|}
\hline \multirow[t]{2}{*}{ Characteristic (N) } & \multicolumn{2}{|l|}{ HIV-LT score } & \multicolumn{2}{|l|}{ HIV-LT10 score $^{a}$} \\
\hline & Median (IQR) or correlation $(\rho)$ & $P$ & Median (IQR) or correlation $(\rho)$ & $P$ \\
\hline General literacy score & 0.8 & $<0.0001$ & 0.7 & $<0.0001$ \\
\hline General numeracy score & 0.7 & $<0.0001$ & 0.7 & $<0.0001$ \\
\hline Education & 0.7 & $<0.0001$ & 0.7 & $<0.0001$ \\
\hline Income & & $<0.0001$ & & \\
\hline 0-5999 meticais (232) & $38(13-56)^{\mathrm{b}}$ & & $30(10-50)^{\mathrm{b}}$ & 0.0001 \\
\hline 6000 meticais or more $(87)$ & $56(38-69)^{\mathrm{b}}$ & & $60(30-70)^{\mathrm{b}}$ & \\
\hline \multicolumn{5}{|l|}{ Job } \\
\hline No job (84) & $50(22-63)^{\mathrm{b}}$ & 0.0001 & $40(20-60)^{\mathrm{b}}$ & 0.0042 \\
\hline Agriculture [51] & $13(6-38)^{\mathrm{b}}$ & & $10(0-40)^{\mathrm{b}}$ & \\
\hline Domestic (25) & $44(31-56)^{\mathrm{b}}$ & & $25(10-50)^{\mathrm{b}}$ & \\
\hline Work outside the home (155) & $50(25-69)^{\mathrm{b}}$ & & $50(20-70)^{\mathrm{b}}$ & \\
\hline \multicolumn{5}{|l|}{ Language spoken at home } \\
\hline Portuguese (109) & $63(44-75)^{b}$ & 0.0001 & $60(40-70)^{\mathrm{b}}$ & 0.0001 \\
\hline Changane (170) & $25(13-50)^{\mathrm{b}}$ & & $20(0-40)^{\mathrm{b}}$ & \\
\hline Ronga (31) & $50(13-63)^{\mathrm{b}}$ & & $45(10-60)^{\mathrm{b}}$ & \\
\hline Other $(9)^{\mathrm{c}}$ & $31(13-38)^{\mathrm{b}}$ & & $40(15-60)^{\mathrm{b}}$ & \\
\hline 90-Day adherence to antiretroviral therapy & -0.01 & 0.79 & 0.001 & 0.99 \\
\hline Total HIV-LT score & Non applicable & Non applicable & 0.96 & $<0.0001$ \\
\hline
\end{tabular}

${ }^{a}$ HIV-LT10 is the 10-item version of the HIV Literacy Test

b The HIV-LT and HIV-LT10 scores each range from 0 to $100 \%$

c Other languages: EChuabo and Chope 


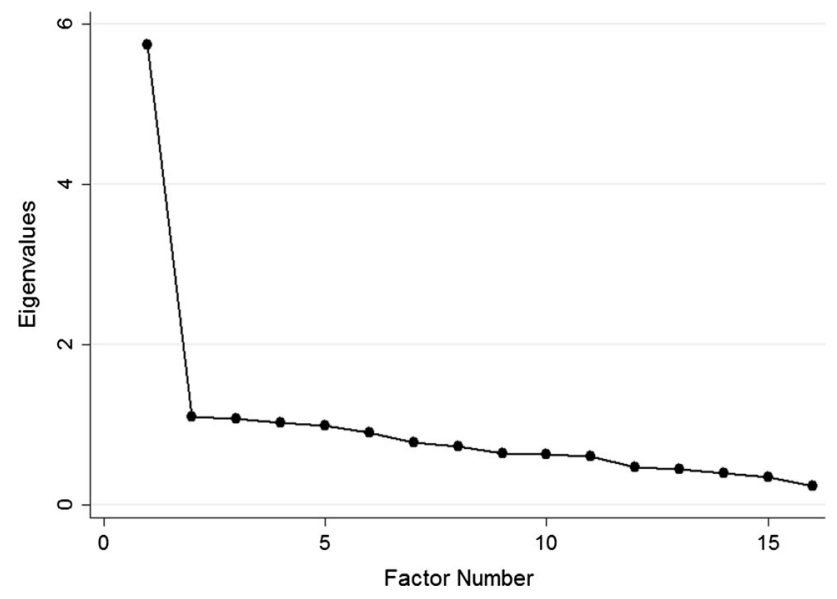

Fig. 4 Scree plot of eigenvalues after Principal Component Analysis with orthogonal rotation

understanding routinely discussed disease-related concepts, such as CD4+ T-lymphocyte cell count. The shortened 10 -item version of the HIV-LT was also proven reliable and valid to measure literacy skills in the same population as the original scale. The HIV-LT10 is potentially more clinically useful, given time constraints of health care providers in low-and-middle income countries.

This study builds on the limited literature to date about health literacy and HIV in sub-Saharan Africa. We found only two other studies conducted in sub-Saharan Africa that have focused on measuring literacy's role on HIVrelated knowledge, behaviors and outcomes. One recent study reported an association between limited literacy and numeracy with lower HIV knowledge [19], and an observational study showed a relationship between higher selfreported literacy and virologic suppression of HIV [46]. Both studies applied suboptimal health literacy measures, since these were not specific to the disease or health context of the studies. The HIV-LT is one of a few examples of measures of health literacy that are specifically applied to HIV/AIDS [30, 32], and is the first to be developed within the sub-Saharan Africa context. Even in high-income countries, with a more substantial body of research on literacy and HIV, measurement of literacy in HIV-infected patients has been performed through the use of tools such as the Test of Functional Health Literacy in Adults (TOFHLA) [22, 34, 47, 48] and the Rapid Estimate of Adult Literacy in Medicine (REALM) [24, 28]. These tools still require patients to perform activities that are not specific to their disease or health condition, to apply quantitative information to a general health activities, or to simply read a set of health related terms. In contrast, the HIV-LT items include basic HIV-related treatment terms that are used routinely in care in Mozambique, and ask patients in treatment for HIV to demonstrate how they apply their range of literacy skills to daily self-management activities related to the disease. In a study conducted in South Africa, the REALM psychometric properties were tested and found inappropriate to measure literacy in the multi-linguistic South African population [17]. While some measures of health literacy have been translated and applied to non-English speaking populations [49], the settings were vastly different from the one found in sub-Saharan Africa. Hence, scales exhibit an inherent cultural bias that limits their use in non-Western populations. The HIVLT items include culturally appropriate language and clinical materials used in daily care in Mozambique. This increases the scale's face validity and may have resonated better with participating patients.

Our study did not yield evidence to support a relationship between health literacy skill and adherence to ART using pharmacy claim data. Our convenience sample of persons in HIV care and taking ART may have selected for more adherent persons. In fact, patients are initiated on ART once they demonstrate the potential for high adherence in Mozambique.

In higher income countries, data linking limited health literacy to lower adherence to ART have had inconsistent results $[23,26-28,30-34,50]$ and the relationship has not been studied previously in sub-Saharan Africa. Published studies have used a variety of methods to assess adherence to ART and health literacy, perhaps explaining the heterogeneity of results. Some studies report adherence to ART using patient recall, a skill that itself may be influenced by literacy $[30,31]$. While pharmacy claim data are objective and straightforward to collect from routinely generated clinical data, they are limited by overestimation of actual pill taking if individuals discard or share pills and, therefore, can be considered to estimate maximum adherence, not likely adherence [51]. On items related to medication administration on the HIV-LT, patients had difficulty interpreting written prescriptions, and errors in interpretation may lead to errors in self-administration of HIV medication that would not necessarily be captured by pharmacy claim data. Half our study participants were patients who had been on ART for at least 2 years. We only assessed their adherence in the last 3 months. These patients may have had problems with adherence early in the treatment, but improved with counseling measures that have been in place in most of the HIV clinics in Mozambique.

Other study limitations include the fact that our assessment of health literacy was made as part of a hypothetical situation that may not reflect patient's actual selfmanagement skills or impact HIV outcomes. The recruitment of a convenience sample of urban and rural patients introduces the possibility of selection bias; patients who were not actively in HIV care, who had not been initiated on ART or who declined to participate may have lower 
literacy skills than those who participated in the study. Thus, health literacy skills among patients might be even worse than we have concluded. Another bias towards more favorable results than would be seen in a representative sample is our exclusion of non-Portuguese speaking patients from this study. Portuguese is the only official language in Mozambique, the language taught in schools, and used in the healthcare setting. Since Mozambican individuals who speak Portuguese have higher levels of education than non-speakers [19], they likely have higher literacy skill, and thus again their overrepresentation is likely to underestimate the magnitude of the relationship between health literacy and HIV-related activities reported in this study. The WRAT-3 scale, which we used to evaluate general literacy skills, is at best a measure of letter and word recognition, and focus primarily on arithmetic computation. However, studies by the WRAT developers and by our group have shown strong correlation between performance on it and other literacy, health literacy, and numeracy skills in other populations [52-56]. On the other hand, the scale was only a part of the construct validity model used and represents one of the most compelling reasons for the need for development of the HIV-LT-a better tool to assess a broader set of HIV related health literacy skills.

Identifying those with limited HIV health literacy is the first step in development of better strategies to communicate health information in a patient centered manner. In the US, an intervention tailored to improve communication of HIV-related information by using pictograph-guided adherence counseling to patients with limited literacy improved ART adherence and undetectable HIV viral loads, compared to patients submitted to general health counseling [57]. Improving health education materials, simplifying commonly used prescription cards and treatment instructions, or applying simple communication strategies such as the "teach-back/feedback model" are a few examples of interventions that can be tested and evaluated using the HIV-LT10 in future studies [48, 5862].

\section{Conclusions}

Health literacy skills are important to the daily management of HIV infection for Mozambican adults. The HIVLT10 was designed to maintain items that assess HIV health literacy, and could more easily be used in the clinical setting to identify patients with limited health literacy skills who may benefit from tailored strategies to better communicate health information. The scale can also be used for future research focused in understanding the role of health literacy as a mediator of HIV-related behaviors and outcomes. Attention to patients and providers health communication skills can help improve the quality of health care, particularly in settings where low literacy is common.

Acknowledgments The authors would like to thank Meridith Blevins and Kenneth Wallston for their assistance with statistical and psychometric analyses. Dr. José A. Tique was funded by AIDS International Training and Research Program, NIH Grant \#D43TW001035. Dr. Leigh Howard was funded by the Childhood Infection Research Program, Training Grant \#IT32AI095202-01. Funders had no role in study design, data collection, analysis, decision to publish or preparation of the article.

Open Access This article is distributed under the terms of the Creative Commons Attribution 4.0 International License (http://crea tivecommons.org/licenses/by/4.0/), which permits unrestricted use, distribution, and reproduction in any medium, provided you give appropriate credit to the original author(s) and the source, provide a link to the Creative Commons license, and indicate if changes were made.

\section{References}

1. Joint United Nations Programme on HIV/AIDS. Global Report: UNAIDS Report on the Global AIDS Epidemic 2013. Geneva: Document UNAIDS/JC2502/1/E. http://www.unaids.org/sites/ default/files/media_asset/UNAIDS_Global_Report_2013_en_1. pdf. Accessed 14 Nov 2015.

2. Yiannoutsos CT, Johnson LF, Boulle A, et al. Estimated mortality of adult HIV-infected patients starting treatment with combination antiretroviral therapy. Sex Transm Infect. 2012;88(Suppl 2):i33-43.

3. Steele KT, Steenhoff AP, Newcomb CW, et al. Early mortality and AIDS progression despite high initial antiretroviral therapy adherence and virologic suppression in Botswana. PLoS One. 2011;6(6):e20010.

4. Ford N, Darder M, Spelman T, Maclean E, Mills E, Boulle A. Early adherence to antiretroviral medication as a predictor of long-term HIV virological suppression: five-year follow up of an observational cohort. PLoS One. 2010;5(5):e10460.

5. Mills EJ, Nachega JB, Bangsberg DR, et al. Adherence to HAART: a systematic review of developed and developing nation patientreported barriers and facilitators. PLoS Med. 2006;3(11):e438.

6. Posse M, Meheus F, van Asten H, van der Ven A, Baltussen R. Barriers to access to antiretroviral treatment in developing countries: a review. Trop Med Int Health. 2008;13(7):904-13.

7. Vermund SH, Tique JA, Cassell HM, Pask ME, Ciampa PJ, Audet CM. Translation of biomedical prevention strategies for HIV: prospects and pitfalls. J Acquir Immune Defic Syndr. 2013;63(Suppl 1):S12-25.

8. Institute of Medicine. Health literacy: a prescription to end confusion. Washington, DC: National Academies Press; 2004.

9. Rothman RL, Montori VM, Cherrington A, Pignone MP. Perspective: the role of numeracy in health care. J Health Commun. 2008;13(6):583-95.

10. Parker RM, Ratzan SC, Lurie N. Health literacy: a policy challenge for advancing high-quality health care. Health Aff (Millwood). 2003;22(4):147-53.

11. Bailey SC, Brega AG, Crutchfield TM, et al. Update on health literacy and diabetes. Diabetes Educ. 2014;40(5):581-604.

12. Rothman R, Malone R, Bryant B, Dewalt D, Pignone M. Health literacy and diabetic control. JAMA. 2002;288(21):2687-8. 
13. Al Sayah F, Majumdar SR, Williams B, Robertson S, Johnson JA. Health literacy and health outcomes in diabetes: a systematic review. J Gen Intern Med. 2013;28(3):444-52.

14. United Nations Development Programme. Human Development Report 2011. Geneva: UNDP. ISBN: 9780230363311. 2011 available at: http://hdr.undp.org/sites/default/files/reports/14/ hdr2013_en_complete.pdf. Accessed 14 Nov 2015.

15. Howard LM, Tique JA, Gaveta S, et al. Health literacy predicts pediatric dosing accuracy for liquid zidovudine. AIDS. 2014;28(7):1041-8.

16. Keikelame MJ, Swartz L. Lost opportunities to improve health literacy: observations in a chronic illness clinic providing care for patients with epilepsy in Cape Town South Africa. Epilepsy Behav. 2013;26(1):36-41.

17. Dowse R, Lecoko L, Ehlers MS. Applicability of the REALM health literacy test to an English second-language South African population. Pharm World Sci. 2010;32(4):464-71.

18. Lori JR, Dahlem CH, Ackah JV, Adanu RM. Examining antenatal health literacy in Ghana. J Nurs Scholarsh. 2014;46(6):432-40.

19. Ciampa PJVL, Blevins M, Sidat M, Rothman RL, Vermund SH, Vergara AE. The association among literacy, numeracy, HIV knowledge and health-seeking behavior: a population-based survey of women in rural Mozambique. PLoS One. 2012;7(6):e39391.

20. McTavish S, Moore S, Harper S, Lynch J. National female literacy, individual socio-economic status, and maternal health care use in sub-Saharan Africa. Soc Sci Med. 2010;71(11):1958-63.

21. Kalichman SC, Benotsch E, Suarez T, Catz S, Miller J, Rompa D. Health literacy and health-related knowledge among persons living with HIV/AIDS. Am J Prev Med. 2000;18(4):325-31.

22. Kalichman SC, Rompa D. Functional health literacy is associated with health status and health-related knowledge in people living with HIV-AIDS. J Acquir Immune Defic Syndr. 2000;25(4): $337-44$.

23. Wolf MS, Davis TC, Cross JT, Marin E, Green K, Bennett CL. Health literacy and patient knowledge in a Southern US HIV clinic. Int J STD AIDS. 2004;15(11):747-52.

24. Wolf MS, Davis TC, Arozullah A, et al. Relation between literacy and HIV treatment knowledge among patients on HAART regimens. AIDS Care. 2005;17(7):863-73.

25. Waldrop-Valverde D, Jones DL, Gould F, Kumar M, Ownby RL. Neurocognition, health-related reading literacy, and numeracy in medication management for HIV infection. AIDS Patient Care STDS. 2010;24(8):477-84.

26. Kalichman SC, Pope H, White D, et al. Association between health literacy and HIV treatment adherence: further evidence from objectively measured medication adherence. J Int Assoc Phys AIDS Care. 2008;7(6):317-23.

27. Kalichman SC, Amaral CM, Stearns H, et al. Adherence to antiretroviral therapy assessed by unannounced pill counts conducted by telephone. J Gen Intern Med. 2007;22(7):1003-6.

28. Osborn CY, Paasche-Orlow MK, Davis TC, Wolf MS. Health literacy: an overlooked factor in understanding HIV health disparities. Am J Prev Med. 2007;33(5):374-8.

29. Waldrop-Valverde D, Osborn CY, Rodriguez A, Rothman RL, Kumar M, Jones DL. Numeracy skills explain racial differences in HIV medication management. AIDS Behav. 2010;14(4): 799-806.

30. Osborn CY, Davis TC, Bailey SC, Wolf MS. Health literacy in the context of HIV treatment: introducing the Brief Estimate of Health Knowledge and Action (BEHKA)-HIV version. AIDS Behav. 2010;14(1):181-8.

31. Kalichman SC, Ramachandran B, Catz S. Adherence to combination antiretroviral therapies in HIV patients of low health literacy. J Gen Intern Med. 1999;14(5):267-73.
32. Ownby RL, Waldrop-Valverde D, Hardigan P, Caballero J, Jacobs R, Acevedo A. Development and validation of a brief computer-administered HIV-Related Health Literacy Scale (HIVHL). AIDS Behav. 2013;17(2):710-8.

33. Miller LG, Liu H, Hays RD, Golin CE, Ye Z, Beck CK, et al. Knowledge of antiretroviral regimen dosing and adherence: a longitudinal study. Clin Infect Dis. 2003;36(4):514-8.

34. Colbert AM, Sereika SM, Erlen JA. Functional health literacy, medication-taking self-efficacy and adherence to antiretroviral therapy. J Adv Nurs. 2013;69(2):295-304.

35. Liu H, Miller LG, Hays RD, et al. A comprehensive evaluation of survey questions for adherence to antiretroviral medications and exploratory analyses for identifying optimal sets of survey questions. AIDS Patient Care STDS. 2006;20(11):760-72.

36. Instituto Nacional de Saúde (INS), Instituto Nacional de Estatística (INE), ICF Macro. Inquérito Nacional de Prevalência, Riscos Comportamentais e Informação sobre o HIV e SIDA em Moçambique 2009. Calverton: INS, INE e ICF; 2009. p. 2010.

37. Parker RM, Baker DW, Williams MV, Nurss JR. The test of functional health literacy in adults: a new instrument for measuring patients' literacy skills. J Gen Intern Med. 1995;10(10):537-41.

38. Kumar D, Sanders L, Perrin EM, et al. Parental understanding of infant health information: health literacy, numeracy, and the Parental Health Literacy Activities Test (PHLAT). Acad Pediatr. 2010;10(5):309-16.

39. Huizinga MM, Elasy TA, Wallston KA, et al. Development and validation of the Diabetes Numeracy Test (DNT). BMC Health Serv Res. 2008;8:96.

40. Sousa VD, Rojjanasrirat W. Translation, adaptation and validation of instruments or scales for use in cross-cultural health care research: a clear and user-friendly guideline. J Eval Clin Pract. 2011;17(2):268-74.

41. Behling O, Law K. Translating questionnaires and other research instruments: problems and solutions. Thousand Oaks: Sage; 2000.

42. Jastak J, Wilkenson G. Wide range achievement test (WRAT-3). 3rd ed. Wilmington: Wide Range Inc.; 1993.

43. Goldman JD, Cantrell RA, Mulenga LB, et al. Simple adherence assessments to predict virologic failure among HIV-infected adults with discordant immunologic and clinical responses to antiretroviral therapy. AIDS Res Hum Retroviruses. 2008;24(8):1031-5.

44. DeVellis R. Scale development: theory and application. 2nd ed. Newbury Park (CA): Sage; 2012.

45. Harris PA, Taylor R, Thielke R, Payne J, Gonzalez N, Conde JG. Research electronic data capture (REDCap) - a metadata-driven methodology and workflow process for providing translational research informatics support. J Biomed Inform. 2009;42(2): 377-81.

46. Hegazi A, Bailey RL, Ahadzie B, Alabi A, Peterson K. Literacy, education and adherence to antiretroviral therapy in The Gambia. AIDS Care. 2010;22(11):1340-5.

47. Drainoni ML, Rajabiun S, Rumptz M, et al. Health literacy of HIV-positive individuals enrolled in an outreach intervention: results of a cross-site analysis. $\mathrm{J}$ Health Commun. 2008;13(3):287-302.

48. Kalichman SC, Cherry J, Cain D. Nurse-delivered antiretroviral treatment adherence intervention for people with low literacy skills and living with HIV/AIDS. J Assoc Nurses AIDS Care. 2005;16(5):3-15.

49. Connor M, Mantwill S, Schulz PJ. Functional health literacy in Switzerland - validation of a German, Italian, and French health literacy test. Patient Educ Couns. 2013;90(1):12-7.

50. Golin CE, Liu H, Hays RD, et al. A prospective study of predictors of adherence to combination antiretroviral medication. J Gen Intern Med. 2002;17(10):756-65. 
51. McMahon JH, Jordan MR, Kelley K, et al. Pharmacy adherence measures to assess adherence to antiretroviral therapy: review of the literature and implications for treatment monitoring. Clin Infect Dis. 2011;52(4):493-506.

52. Cavanaugh K, Huizinga MM, Wallston KA, et al. Association of numeracy and diabetes control. Ann Intern Med. 2008;148(10):737-46.

53. Osborn CY, Wallston KA, Shpigel A, Cavanaugh K, Kripalani S, Rothman RL. Development and validation of the General Health Numeracy Test (GHNT). Patient Educ Couns. 2013;91(3):350-6.

54. Yin HS, Sanders LM, Rothman RL, et al. Assessment of health literacy and numeracy among Spanish-Speaking parents of young children: validation of the Spanish Parental Health Literacy Activities Test (PHLAT Spanish). Acad Pediatr. 2012;12(1): 68-74.

55. Al Sayah F, Williams B, Johnson JA. Measuring health literacy in individuals with diabetes: a systematic review and evaluation of available measures. Health Educ Behav. 2013;40(1):42-55.

56. Dewalt DA, Berkman ND, Sheridan S, Lohr KN, Pignone MP. Literacy and health outcomes: a systematic review of the literature. J Gen Intern Med. 2004;19(12):1228-39.
57. Weidle PJ, Wamai N, Solberg P, et al. Adherence to antiretroviral therapy in a home-based AIDS care programme in rural Uganda. Lancet. 2006;368(9547):1587-94.

58. Doak C, Doak L, Root J. Teaching patients with low literacy skills. 2nd ed. Philadelphia: JB Lippincott Company; 1996.

59. Mayeaux EJ Jr, Murphy PW, Arnold C, Davis TC, Jackson RH, Sentell T. Improving patient education for patients with low literacy skills. Am Fam Phys. 1996;53(1):205-11.

60. Kripalani S, Weiss BD. Teaching about health literacy and clear communication. J Gen Intern Med. 2006;21(8):888-90.

61. Vermund SH, Van Lith LM, Holtgrave D. Strategic roles for health communication in combination HIV prevention and care programs. J Acquir Immune Defic Syndr. 2014;66(Suppl 3):S237-40.

62. Tomori C, Risher K, Limaye RJ, et al. A role for health communication in the continuum of HIV care, treatment, and prevention. J Acquir Immune Defic Syndr. 2014;66(Suppl 3):S306-10. 